\title{
Developing a neuro-fuzzy system to classify drainage sub-basins according to erosion processes on the Island of Lefkas, Greece
}

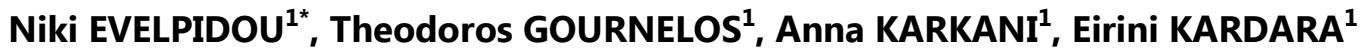 \\ ${ }^{1}$ Faculty of Geology and Geoenvironment, National and Kapodistrian University of Athens, \\ Panepistimiopolis 15784, Athens, Greece
}

Received 2 August 2018; Revised 30 November 2018; Accepted 12 December 2018

*Correspondence to: Niki EVELPIDOU, e-mail: evelpidou@geol.uoa.gr

\begin{abstract}
In this paper we attempt to classify drainage sub-basins according to their erosion risk. We have adopted a multistep procedure to face this problem. The input variables were introduced into a GIS - platform. These variables were the vulnerability of the surface rocks to erosion, topographic variations, vegetation cover, land use and drainage basin characteristics. We constructed a fuzzy inference mechanism to pre-process the input variables. Next we used neural-network technology to process the input variables. The system was trained to 'learn' and classify the input data. The output of this procedure was a classification of the sub-drainage basins related to their risk of erosion. This neuro-fuzzy system was applied to the island of Lefkas (Greece).
\end{abstract}

KEYWORDS

erosion; fuzzy sets; neural networks; GIS; Ionian Sea

\section{Introduction}

Environmental settings such as geological, geomorphological and climatic conditions affect drainage structures. Characteristics of rocks and soils, geographical distribution and intensity of rainfall, along with micro-topography, determine surface and underground water. Runoff can be either Hortonian or not depending on the infiltration capacity of surface rocks. Emmet (1978) has stated that the flow characteristics of the surface waters may produce rills or sheet flow, and as a result, weathered material can be transferred by water movement. Tem- 
poral and spatial aspects also affect erosional processes. Splash erosion, caused by raindrop impact, seems to greatly influence the detachment of material. According to Kirkby (1978), the rate of soil erosion is proportional to the distance from the divide multiplied by the power of slope gradient. The phenomenon of soil erosion has been studied by many researchers (Stocking, Elwell, 1973; Elwell, 1978;
Wischmeier and Smith, 1978; Morgan et al., 1984; Nearing et al., 1989; Briggs and Giordano, 1992; Thornes et al., 1996; Baturst et al., 1996; Koulouri and Giourga, 2007; Cerdan et al., 2010). Some methodologies of artificial intelligence, especially fuzzy set theory, have also been previously applied to erosion issues by Burrough (1989), Burrough et al. (1992), Gournelos et al. (2005).

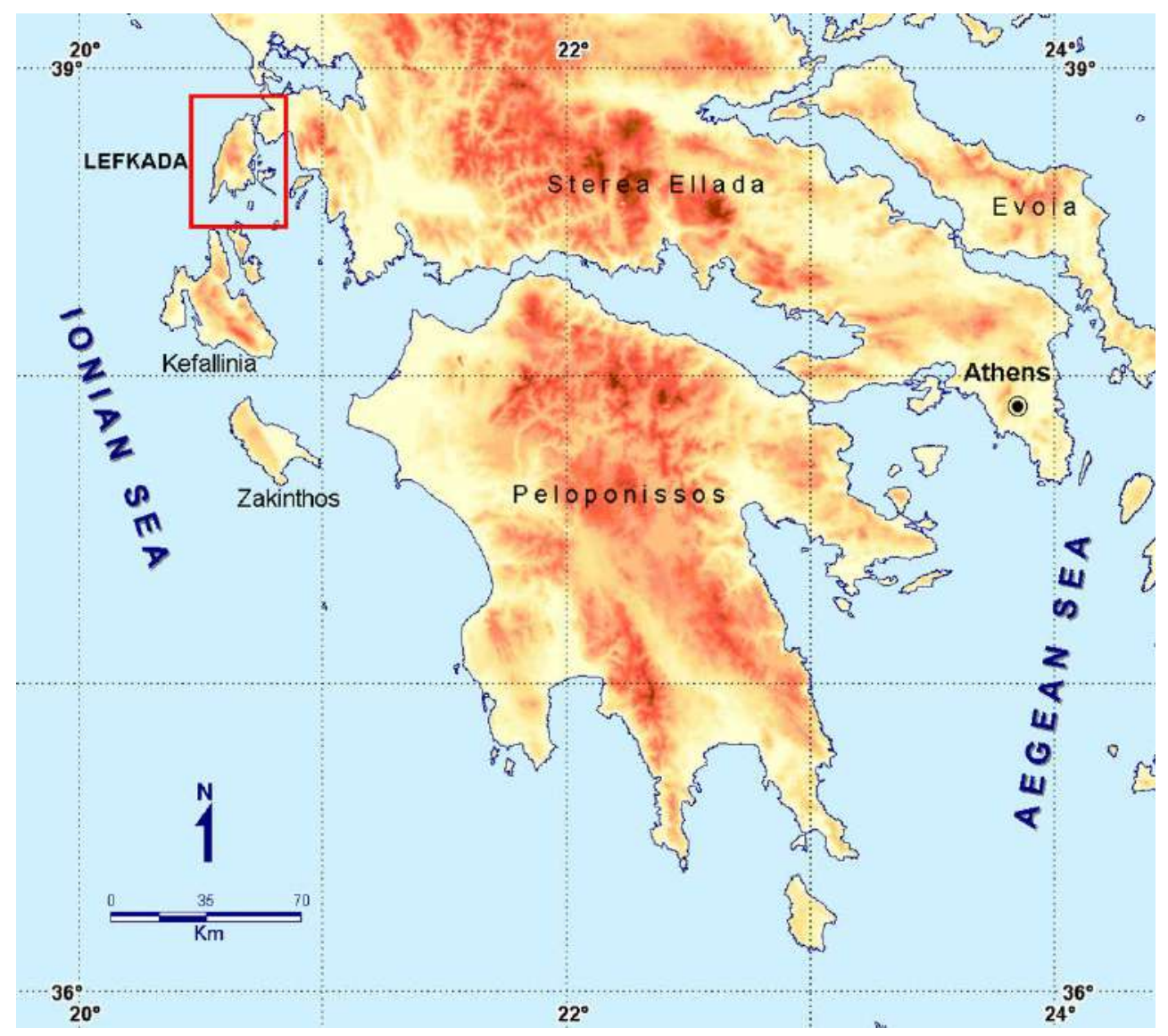

Figure 1 Location of the study area

In addition to the natural modification of drainage basins, human induced factors also play an important role: activities such as the expansion of agricultural areas, building activity and fires greatly affect erosion rates. Soils are key to ecosystems and human societies, and their critical importance requires a better understanding of how they evolve through time. However, identifying the role of natural climate change versus human activity (e.g. agriculture) on soil evolution is difficult (Rothacker et al., 2018).

The Mediterranean region is particularly vulnerable to erosion. This is primarily owed to major land-use changes during the last decades and the long dry periods followed by intensive and erosive rainfall, particularly on areas of steep slopes with fragile soils, (Van der Kniiff et al., 1999).

In this paper, the combination of fuzzy set theory and neural network technology constitutes an innovative methodology that was used to study erosion processes, by generating classifications of autonomous drainage units. All variables affecting and defining erosion were considered here, and the methodology was applied on the island of Lefkas. 


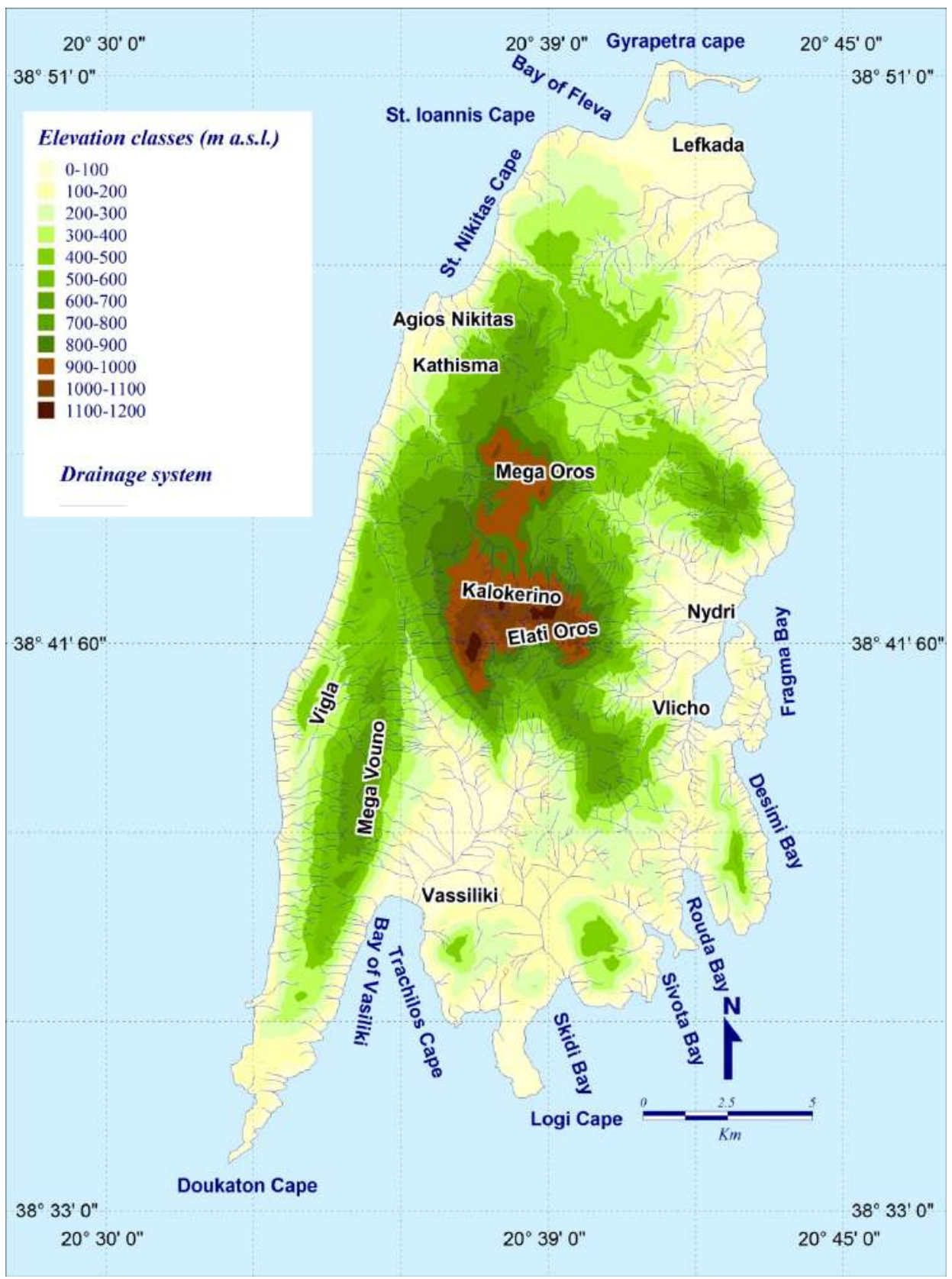

Figure 2 The hipsometry of Lefkas island

\section{Study area}

Lefkas Island is located in the Ionian Sea, in the western part of Greece (Fig. 1) and covers an area of $294 \mathrm{~km}^{2}$. The island is mainly characterized by mountainous and hilly landscapes and a few basins of low altitude (Fig. 2). It is composed of alpine and post-alpine rock formations, some of which are extremely vulnerable to erosion processes. The geological study of Lefkas has been the object of several studies, such as Bornovas (1964), Verginis
(1976), Livaditis and Verikiou-Papaspiridakou (1987) and Underhill (1989). The study area is composed of two geotectonic units, Ionian and Paxoi. The greater part of Lefkas is covered by the Ionian unit (210 $\mathrm{km}^{2}$ ) while the Paxoi unit is located in the southwest part of the island (covering an area of $63 \mathrm{~km}^{2}$ ). The main lithologies of the alpine substratum are limestones and flysch. There are also some Neogene and Quaternary formations in the internal and coastal basins of the island (Fig. 3). It becomes clear 
from the lithological composition that some of the island's surface rock formations are extremely vulnerable to weathering and erosion processes.

The island's annual precipitation levels are relatively high (mean value: $942.3 \mathrm{~mm} /$ year. for the years 1975-1997; Nastos, 2001). Lefkas belongs to a zone of high seismicity. A recent earthquake with a magnitude of $6.4(14 / 08 / 03)$ resulted in a number of landslides in its western part, where steep slopes are dominant (Fig. 2).

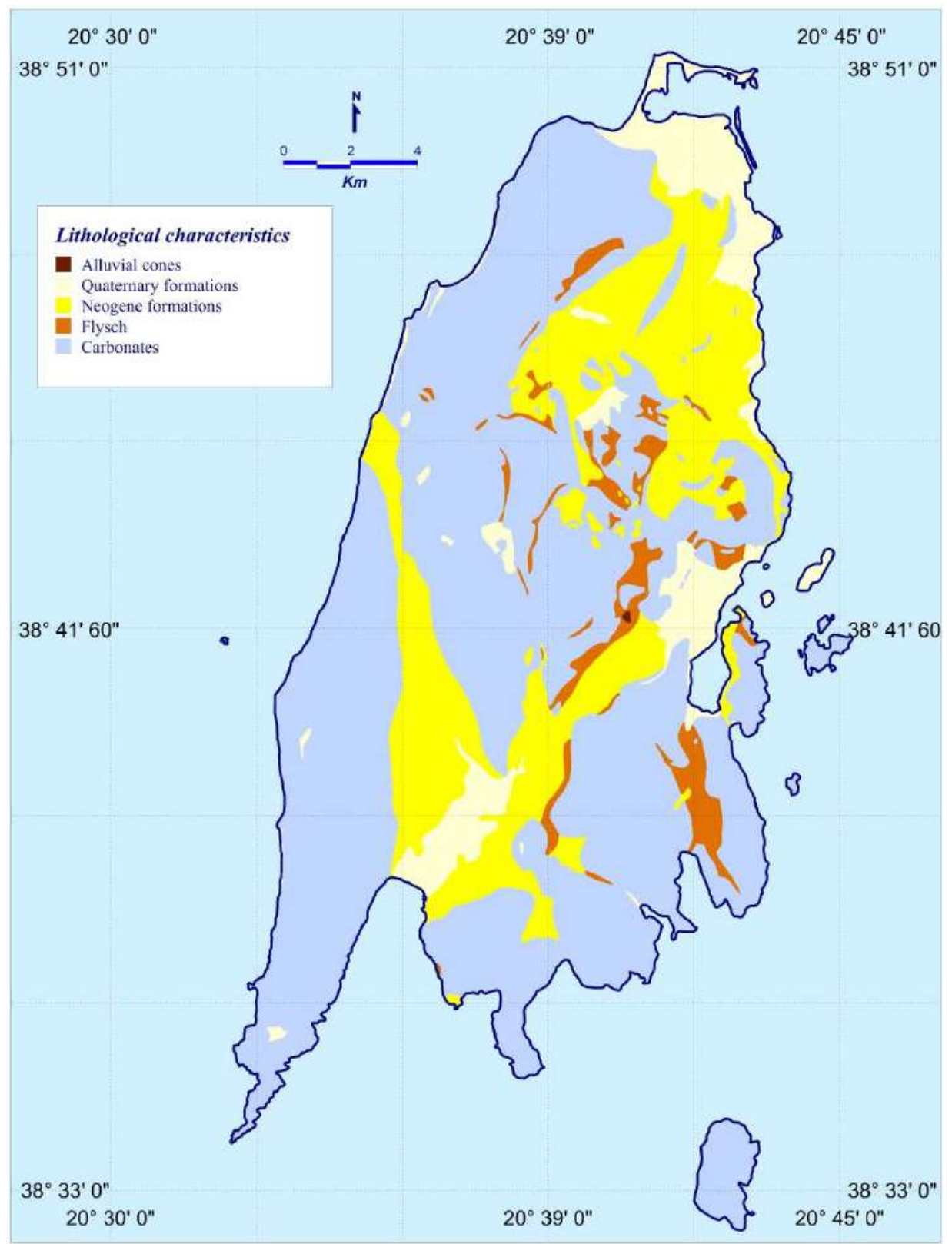

Figure 3 Lithological formations of Lefkas island

\section{Methodology}

In order to study a process as complex as erosion, it was deemed necessary to develop a GIS-based procedure. Firstly, data from various thematic maps, aerial-photos and fieldwork were digitized and im- ported into a GIS (MapInfo 2006). Secondly, the definition of the input and output variables was accomplished. The input variables that were processed are the following: vulnerability of surface rocks to erosion, vegetation cover and land use, drainage characteristics and slope gradient. 
The three first variables are closely related to the erodibility of rocks. Rock vulnerability to erosion is the result of several physical and chemical factors, such as rock composition and structure and the presence or absence of protective vegetation. Vegetation and land use firstly control the infiltration mechanism and hence water runoff (sheet flow or rills), and secondly they affect the impact of precip- itation (Kirkby, 1995). The drainage network is the result of an established surface and subsurface flow system. The drainage system characteristics were studied by using the drainage density variable. The slope gradient determines the surface flow regime. This flow system becomes very erosive when the terrain morphology is dominated by steep slopes.

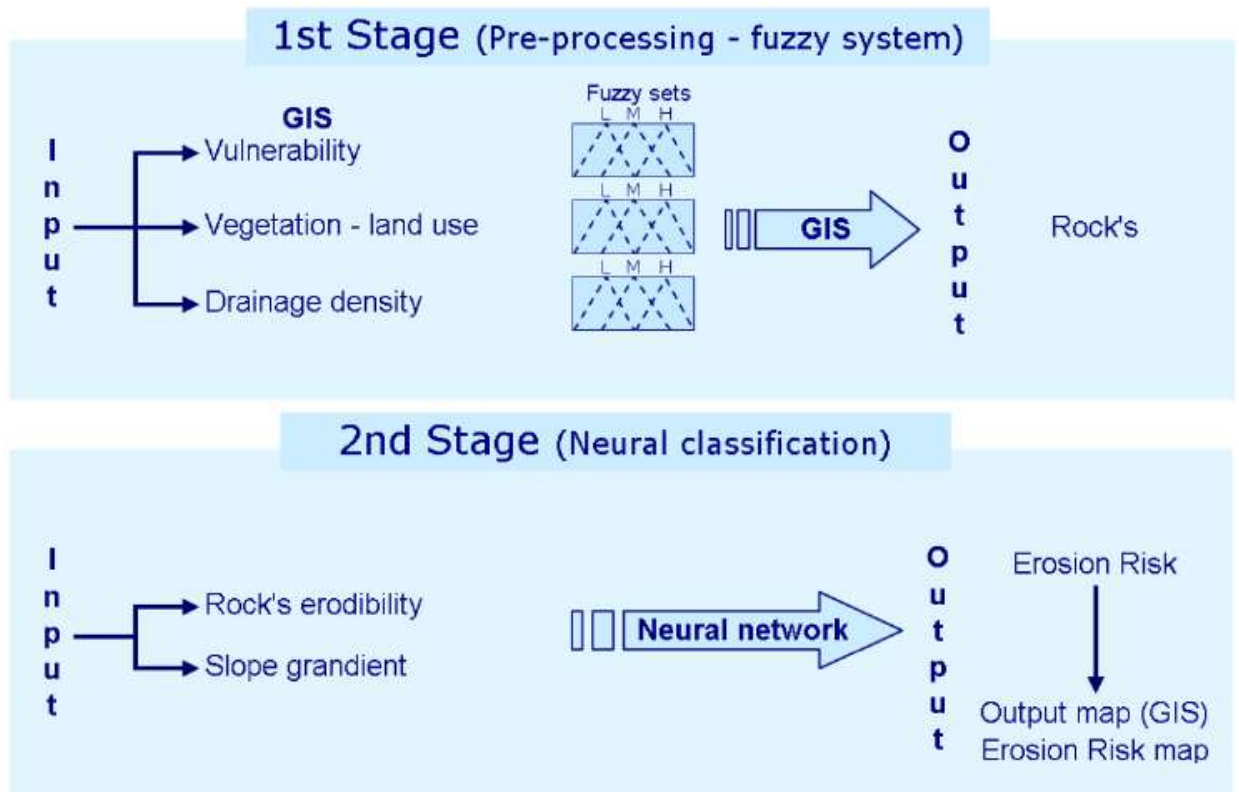

Figure 4 A neural-fuzzy system to produce erosion risk map

Erosion risk was the output variable. The subbasins of the drainage system constituted the basic units for the evaluation of the input variables.

The next step was to establish an interference mechanism with which to transform the input parameters into output parameters. This process consisted of two stages: a fuzzy-based transformation and the creation of a neural network system (Fig. 4). In the first stage the input variables used were: a) rock vulnerability to erosion, b) vegetation - land use, and c) drainage density. The output variable was the rock's erodibility to erosion. All the aforementioned variables present problems of imprecision in terms of their quantification and the definition of their spatial boundaries. For this reason, it was necessary to use fuzzy set theory (Zimmermann, 1991; Klir and Yuan, 1995) (Fig. 4). The fuzzy model was produced by assigning an appropriate membership function to all variables involved and by using logical rules as a transformational mechanism
(Mamdani and Assilion, 1975). The formulation of fuzzy logical rules (Table 1) was based on numerous field observations and the authors' experience of erosion processes. The system's output is of a fuzzy nature. Therefore, defuzzification was carried out, using the centroid technique.

In the second stage we developed an artificial neural network model to classify the drainage subbasins. In this model the input variables were rock erodibility, as derived from the fuzzy model, and slope steepness. In the neural network model, we constructed a three-neuron layer to classify the subbasins according to the degree of erosion risk (Fig. 5). We used competitive learning architecture, which is based on the distance between data input and the weight. The winning neuron is the one with the minimum distance. This process is repeated until all input data are classified (Kohonen, 1982; Rumelhart and Zipser, 1985). 
Table 1 Fuzzy interfaces rules

\begin{tabular}{|c|c|c|c|c|}
\hline $\begin{array}{l}\text { If VULNERABILITY } \\
\text { IS High }\end{array}$ & $\&$ & $\begin{array}{c}\text { VEGETATION - LAND USE INDEX IS Low } \\
\& \text { SLOPE IS High-Medium }\end{array}$ & & $\begin{array}{r}\text { Then ERODIBILITY of } \\
\text { ROCKS Is High }\end{array}$ \\
\hline $\begin{array}{l}\text { If VULNERABILITY } \\
\text { IS High }\end{array}$ & $\&$ & $\begin{array}{c}\text { VEGETATION - LAND USE INDEX IS LOW } \\
\& \text { SLOPE IS LOW }\end{array}$ & & $\begin{array}{l}\text { Then ERODIBILITY of } \\
\text { ROCKS Is Medium }\end{array}$ \\
\hline $\begin{array}{l}\text { If VULNERABILITY } \\
\text { IS High }\end{array}$ & $\&$ & $\begin{array}{c}\text { VEGETATION - LAND USE INDEX IS Low-Medium } \\
\& \text { SLOPE IS Low }\end{array}$ & & $\begin{array}{l}\text { Then ERODIBILITY of } \\
\text { ROCKS Is Medium }\end{array}$ \\
\hline $\begin{array}{l}\text { If VULNERABILITY } \\
\text { IS Medium }\end{array}$ & $\&$ & $\begin{array}{c}\text { VEGETATION - LAND USE INDEX IS LOW } \\
\& \text { SLOPE IS High }\end{array}$ & & $\begin{array}{r}\text { Then ERODIBILITY of } \\
\text { ROCKS Is High }\end{array}$ \\
\hline $\begin{array}{l}\text { If VULNERABILITY } \\
\text { IS Medium }\end{array}$ & $\&$ & $\begin{array}{l}\text { VEGETATION - LAND USE INDEX IS Low } \\
\& \text { SLOPE IS Medium-Low }\end{array}$ & & $\begin{array}{l}\text { Then ERODIBILITY of } \\
\text { ROCKS Is Medium }\end{array}$ \\
\hline $\begin{array}{l}\text { If VULNERABILITY } \\
\text { IS Medium }\end{array}$ & $\&$ & $\begin{array}{c}\text { VEGETATION - LAND USE INDEX IS Medium } \\
\& \text { SLOPE IS High }\end{array}$ & & $\begin{array}{l}\text { Then ERODIBILITY of } \\
\text { ROCKS Is Medium }\end{array}$ \\
\hline $\begin{array}{l}\text { If VULNERABILITY } \\
\text { IS Medium }\end{array}$ & $\&$ & $\begin{array}{c}\text { VEGETATION - LAND USE INDEX IS Medium } \\
\& \text { SLOPE IS Medium }\end{array}$ & $\begin{array}{l}\text { \& Drainage density } \\
\text { IS Medium Low }\end{array}$ & $\begin{array}{r}\text { Then ERODIBILITY of } \\
\text { ROCKS Is Low }\end{array}$ \\
\hline $\begin{array}{l}\text { If VULNERABILITY } \\
\text { IS Medium }\end{array}$ & $\&$ & $\begin{array}{c}\text { VEGETATION - LAND USE INDEX IS Medium } \\
\text { \& SLOPE IS Low }\end{array}$ & $\begin{array}{l}\text { \& Drainage density } \\
\text { IS Medium-Low }\end{array}$ & $\begin{array}{l}\text { Then ERODIBILITY of } \\
\text { ROCKS Is Medium }\end{array}$ \\
\hline
\end{tabular}

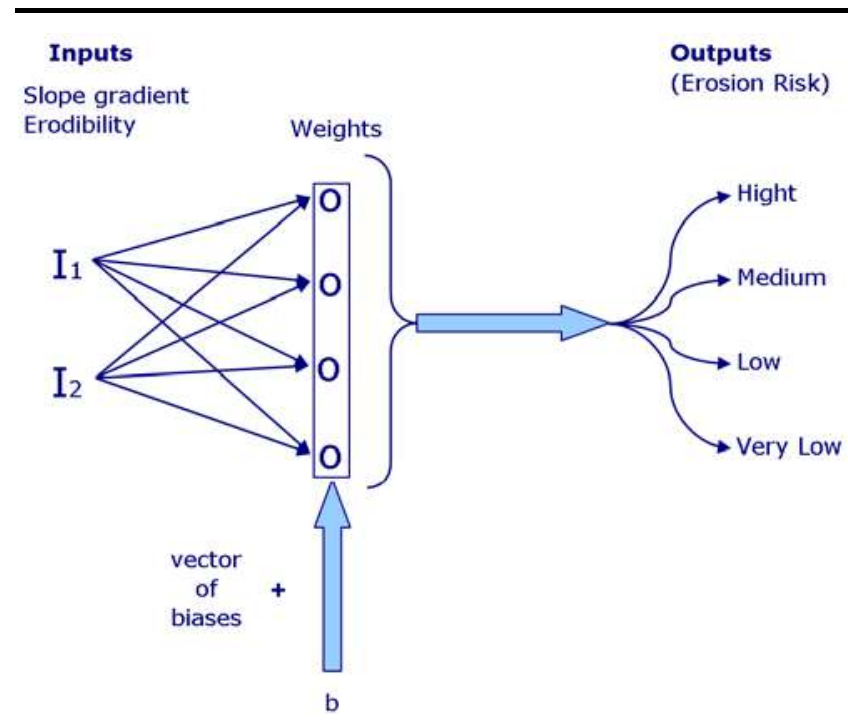

Figure $5 \mathrm{~A}$ three-neuron layer was used with biases

The erosion risk was the output variable of this final stage. The implementation of the aforementioned procedures was achieved using a G.I.S. (MapInfo 2006) and the Matlab software platform (Mat-lab 2005). The fuzzy model and the artificial neural network model were constructed in a Matlab environment loosely coupled with the G.I.S. The values of the input variables were obtained by digitizing topographic and geological maps (1:50.000 Geographic Military Service; Bornovas, 1964), by analyzing aerial photos $(1: 33.000,1986)$ and satellite images (Landsat, 1980) and through field observations.

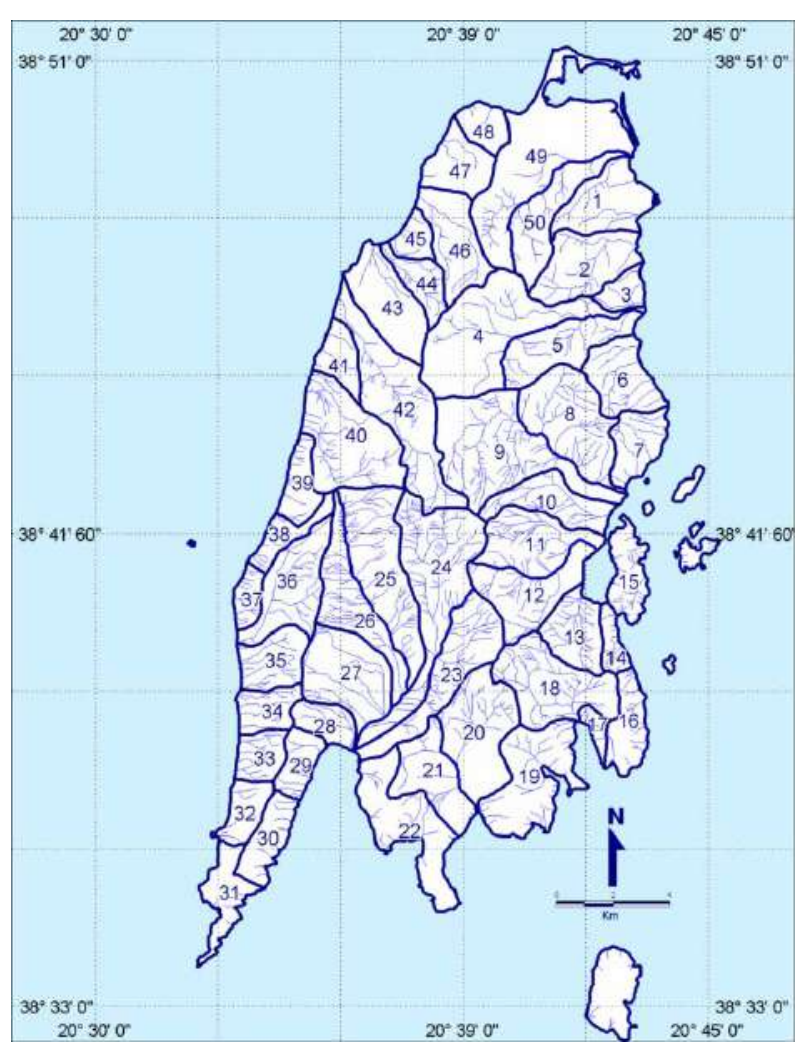

Figure 6 The drainage basins of the island of Lefkas

In the fuzzy model, triangular functions were adopted in the pre-processing stage. All variables were characterized by fuzzy set values, and were expressed with the appropriate membership function. In the present study, "low", "medium" and "high" define the different degrees of rock vulnerability. Rock vulnerability values for Lefkas were 
based on empirical knowledge, field observations and published material (Kuenen, 1956; Leopold et al., 1964; Sparks, 1965; Bolton, 1979; Selby, 1987). We assigned high vulnerability values to the Quaternary and Neogene formations (marls, conglomerates), medium values to the flysch formations and low values to the limestones. The slope gradient and
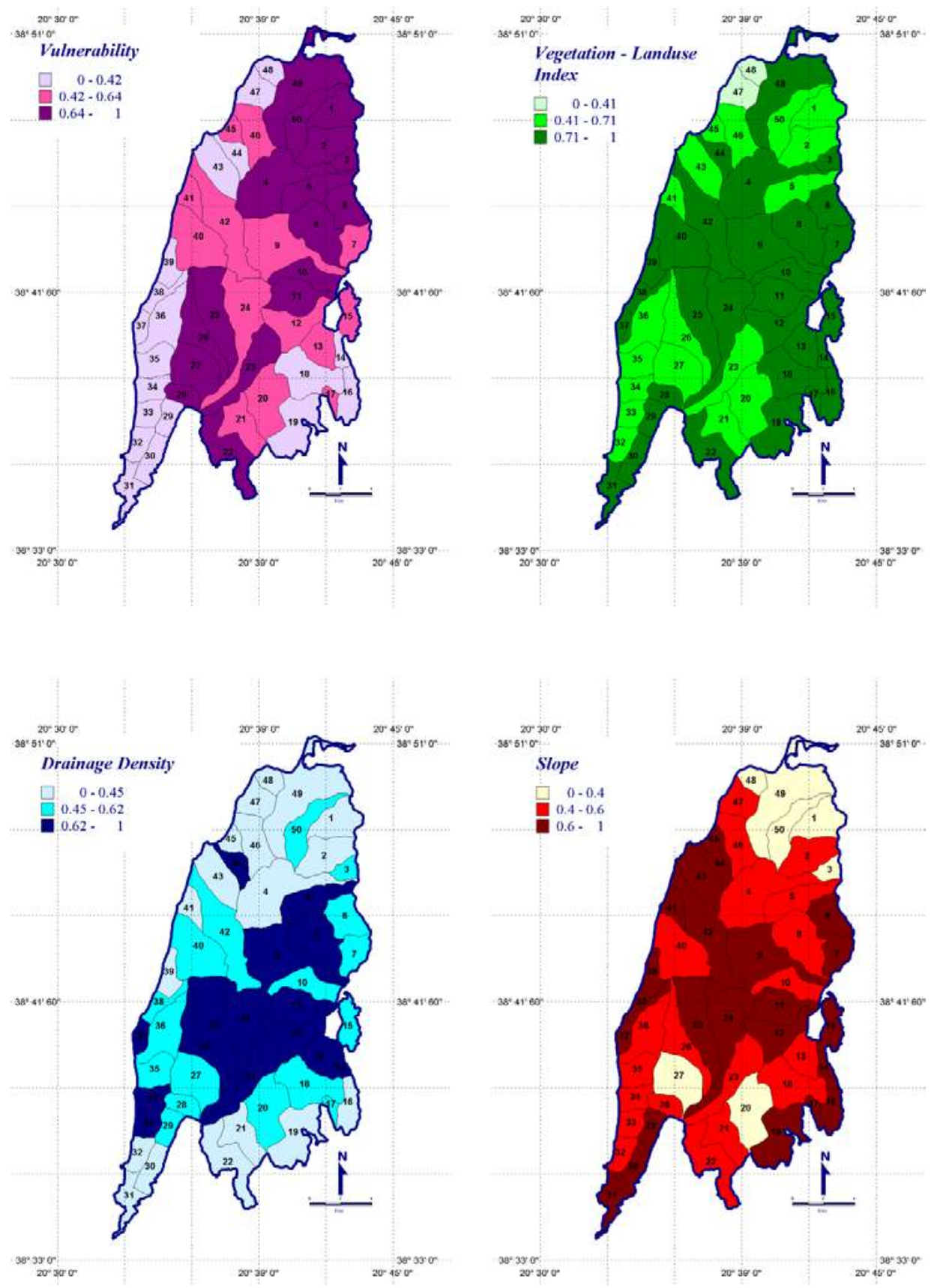

Figure 7 The input variables used in order to extract the erosion risk variable, a) vulnerability, b) vegetation-land use, c) drainage density and d) slope 
EVELPIDOU et al. / Revista de Geomorfologie 20 (2018)

Table 2 Input variables

\begin{tabular}{|c|c|c|c|c|}
\hline Id & $\begin{array}{l}\text { Vulnerability } \\
\text { Normalized }\end{array}$ & $\begin{array}{c}\text { Vegetation - Land use Index } \\
\text { Normalized }\end{array}$ & $\begin{array}{l}\text { Drainage Density } \\
\text { Normalized }\end{array}$ & $\begin{array}{l}\text { Slope gradient } \\
\text { Normalized }\end{array}$ \\
\hline 1 & 1.00 & 0.62 & 0.36 & 0.26 \\
\hline 2 & 0.92 & 0.54 & 0.44 & 0.42 \\
\hline 3 & 0.98 & 0.85 & 0.59 & 0.39 \\
\hline 4 & 0.74 & 0.90 & 0.27 & 0.49 \\
\hline 5 & 0.73 & 0.64 & 0.68 & 0.43 \\
\hline 6 & 0.79 & 0.81 & 0.48 & 0.63 \\
\hline 7 & 0.61 & 0.85 & 0.48 & 0.68 \\
\hline 8 & 0.67 & 0.94 & 0.71 & 0.51 \\
\hline 9 & 0.52 & 0.98 & 0.62 & 0.66 \\
\hline 10 & 0.75 & 0.85 & 0.58 & 0.52 \\
\hline 11 & 0.77 & 0.90 & 0.73 & 0.83 \\
\hline 12 & 0.56 & 0.97 & 0.62 & 0.80 \\
\hline 13 & 0.53 & 0.90 & 0.69 & 0.59 \\
\hline 14 & 0.39 & 0.95 & 0.66 & 0.72 \\
\hline 15 & 0.53 & 0.83 & 0.60 & 0.72 \\
\hline 16 & 0.38 & 0.97 & 0.45 & 0.94 \\
\hline 17 & 0.47 & 0.88 & 0.46 & 0.85 \\
\hline 18 & 0.42 & 0.91 & 0.61 & 0.49 \\
\hline 19 & 0.37 & 0.80 & 0.37 & 0.62 \\
\hline 20 & 0.49 & 0.64 & 0.46 & 0.34 \\
\hline 21 & 0.52 & 0.62 & 0.39 & 0.41 \\
\hline 22 & 0.79 & 0.98 & 0.26 & 0.55 \\
\hline 23 & 0.85 & 0.58 & 0.68 & 0.60 \\
\hline 24 & 0.58 & 0.96 & 0.79 & 0.65 \\
\hline 25 & 0.70 & 0.90 & 0.78 & 0.72 \\
\hline 26 & 0.82 & 0.55 & 1.00 & 0.43 \\
\hline 27 & 0.81 & 0.64 & 0.46 & 0.37 \\
\hline 28 & 0.64 & 0.91 & 0.48 & 0.49 \\
\hline 29 & 0.36 & 0.99 & 0.54 & 0.81 \\
\hline 30 & 0.37 & 0.98 & 0.31 & 0.65 \\
\hline 31 & 0.39 & 1.00 & 0.14 & 0.74 \\
\hline 32 & 0.36 & 0.61 & 0.30 & 0.55 \\
\hline 33 & 0.38 & 0.52 & 0.69 & 0.60 \\
\hline 34 & 0.38 & 0.52 & 0.67 & 0.55 \\
\hline 35 & 0.36 & 0.64 & 0.61 & 0.57 \\
\hline 36 & 0.37 & 0.61 & 0.59 & 0.44 \\
\hline 37 & 0.36 & 0.95 & 0.70 & 0.87 \\
\hline 38 & 0.36 & 0.82 & 0.58 & 0.72 \\
\hline 39 & 0.36 & 0.81 & 0.41 & 1.00 \\
\hline 40 & 0.50 & 0.90 & 0.50 & 0.60 \\
\hline 41 & 0.55 & 0.57 & 0.24 & 0.61 \\
\hline 42 & 0.44 & 0.98 & 0.46 & 0.61 \\
\hline 43 & 0.39 & 0.60 & 0.19 & 0.63 \\
\hline 44 & 0.39 & 0.83 & 0.62 & 0.80 \\
\hline 45 & 0.42 & 0.57 & 0.32 & 0.75 \\
\hline 46 & 0.48 & 0.62 & 0.34 & 0.58 \\
\hline 47 & 0.38 & 0.11 & 0.18 & 0.44 \\
\hline 48 & 0.36 & 0.16 & 0.14 & 0.40 \\
\hline 49 & 0.81 & 0.81 & 0.24 & 0.27 \\
\hline 50 & 0.79 & 0.59 & 0.56 & 0.37 \\
\hline
\end{tabular}


We used the same fuzzy classes for the drainage density and vegetation - land use variables. Thus, low index values for vegetation and land use indicate drainage basins with sparse or no vegetation, medium values indicate underdeveloped vegetation cover, whereas high values signify relatively dense vegetation cover.

The drainage network is defined by topography and surface rock formations. We have identified 50 drainage sub-basins for the whole island (Fig. 6). In order to combine data layers, all the original data were normalized by dividing them by their maxi- mum value. All normalized values are presented in Table 2.

Using the rules of Table 1, mapping of the three input variables was accomplished, rock vulnerability, vegetation/land use and drainage density (Fig. 7a, b, c), in order to create the output variable, the rock's erodibility. The erodibility variable was then combined with slope steepness (Fig. 7d) within the developed neural network to create the erosion risk variable. The final output variable of this neurofuzzy system was the erosion risk for all the drainage sub-basins on Lefkas (Fig. 8).

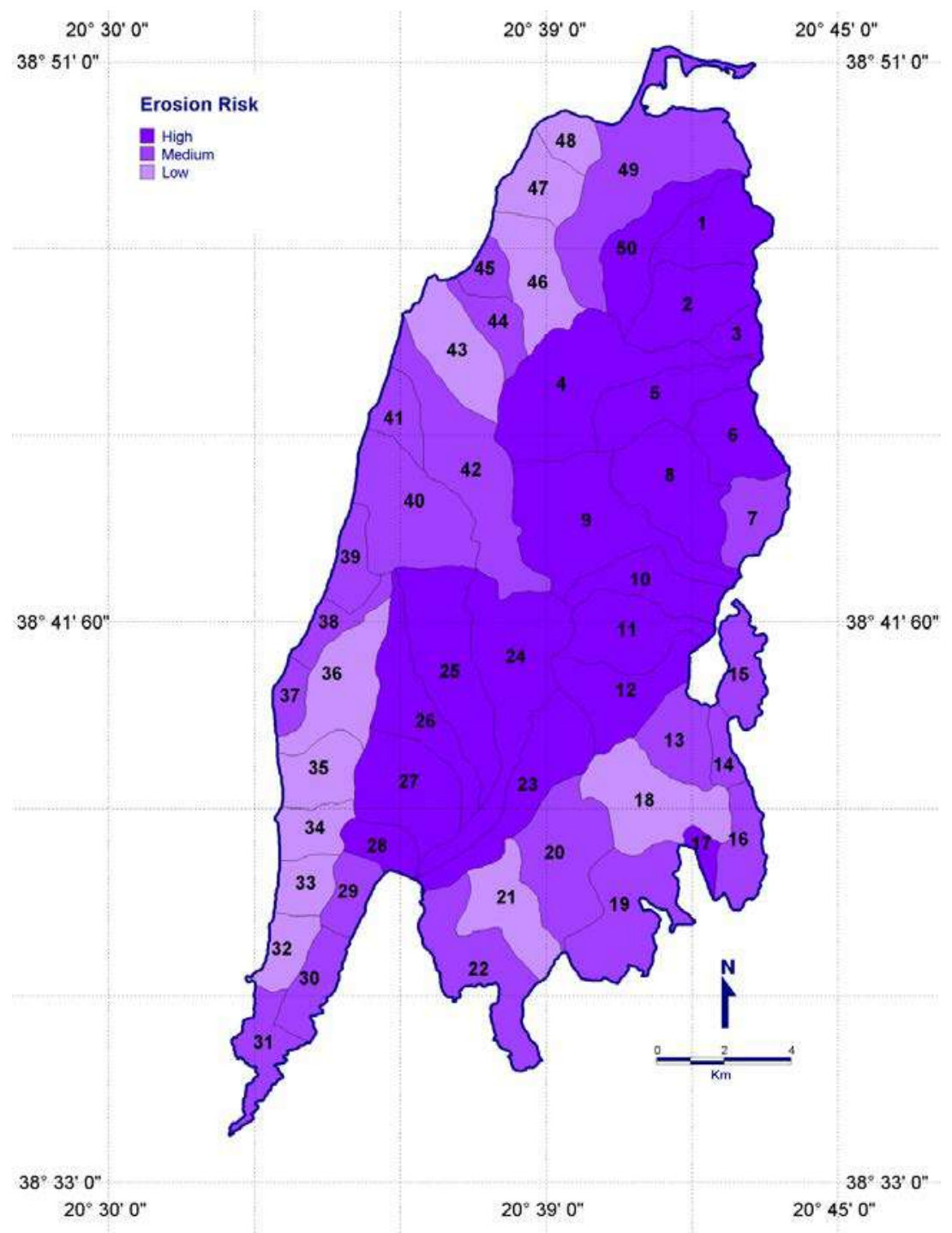

Figure 8 Erosion Risk index of all the drainage sub-basins on Lefkas

\section{Discussion and conclusions}

In the case of Lefkas island, we established three classes of erosion risk: high, medium and low. A sensitivity analysis was carried out in order to test the model's behavior to minimal changes in the input variables. As was expected, small perturba- 
tions in the values of the three input variables cause no significant changes in the output variables (i.e. the erosion risk index).

We have established three classes of erosion risk: high, medium and low (Fig. 8). The drainage sub-basins belonging to the upper classes (high erosion risk) are situated in the northeastern and the southern parts of the island. The medium risk drainage sub-basins are situated in the central part, while the low risk basins are located mainly in the eastern part. The spatial distribution of the erosion risk index variable may be primarily related to the spatial distribution of the lithological formations: where highly vulnerable rocks are present (Neogene and Quaternary) high risk drainage sub-basins are also located, whereas low risk drainage sub-basins are situated in locations with rocks that are more resistant to erosion (limestones). The whole classification scheme takes into account all the input variables involved, especially the nature of surface rocks and topography.

This neuro-fuzzy approach for studying erosional processes is an extremely practical tool because of its ability to handle and classify qualitative data. Erosion risk maps, such as the one produced for Lefkas Island, may be used to identify areas of risk and for the implementation of mitigation measures to protect agricultural and urban areas. This relatively simple model may be used in localand region-level planning, environmental protection and hazard assessments. This methodology may be further improved by using smaller scale grid - based data as elementary input variables.

\section{References}

Baturst JC, Kilsby C, White S. 1996. Modeling the impacts of climate and land-use change on basin hydrology and soil erosion in Mediterranean Europe. In: Brandt J, Thornes JB. (eds.): Mediterranean desertification. Wiley, Chichester, 354-387.

Bolton M. 1979. A Guide to soil mechanics. McMillan, London.

Bornovas J. 1964. Geological study of Leukada island. IGSR, X(1): 142.

Briggs D, Giordano A. 1992. CORINE soil erosion risk and important land resources in the southern regions of the European Community. Commission of the European Communities Publication EUR 13233 EN.
Burrough PA, MacMillan RA, van Deursen W. 1992. Fuzzy classification methods for determining land suitability from soil profile observations and topography. Journal of Soil Science, 43: 193-210.

Burrough PA. 1989. Fuzzy mathematical methods for soil survey and land evaluation, Journal of Soil Science, 40: 477-492.

Cerdan O, Govers G, Le Bissonnais Y, Van Oost K, Poesen J, Saby N, Gobin A, Vacca A, Quinton J, Auerswald K., Klik A. 2010. Rates and spatial variations of soil erosion in Europe: a study based on erosion plot data. Geomorphology, 122(1-2):167-177.

Elwell HA. 1978. Modeling soil losses in Southern Africa. Journal of Agricultural Engineering Research, 23: 117-27.

Geographic Military Service, 1963. Geological map of Leukas, 1:50.000.

Gournelos Th, Evelpidou N, Vassilopoulos A. 2005. Developing an Erosion Risk Map using soft computing methods (case study at Sifnos island). Natural Hazards, 31(1): 63-83.

Kirkby MJ. 1978. Implications for sediment transport. In: Kirkby MJ. (ed.): Hillslope Hydrology. John Wiley, Chichester, 325-340.

Kirkby MJ. 1995. Modeling the links between vegetation and landforms. Geomorphology, 13(1-4): 319-335. DOI: 10.1016/0169-555X(95)00065-D

Klir GJ, Yuan B. 1995. Fuzzy Sets and Fuzzy Logic theory and applications. Prentice-Hall, New Jersey.

Koulouri M, Giourga C. 2007. Land abandonment and slope gradient as key factors of soil erosion in Mediterranean terraced lands. Catena, 69(3): 274-281.

Kuenen PH 1956. Rolling by current (Pt) 2 of Experimental abrasion of pebbles. Journal of Geology, 64: 336-368.

Leopold LB, Wolman MG, Millet JP. 1964. Fluvial processes in Geomorphology. Fraeman WH and Company, San Francisco.

Livaditis G, Verikiou-Papaspiridakou E. 1987. Coastal morphology of Leukas island. Proceedings of 1st PanHellenic Geographical Conference. 387-394.

Mamdani EH, Assilian S. 1975. An experiment in linguistic synthesis with a fuzzy logic controller. International Journal of Man-Machine Studies, 7(1): 1-13.

Morgan RPC, Morgan DDV, Finney HJ. 1984. A predictive model for the assessment of soil erosion risk. Journal of Agricultural Engineering Research, 30: 245-53.

Nastos P. 2001. Geographical distribution of precipitation in Greece. $9^{\text {th }}$ International Congress of Hellenic Geological Association, Athens, XXXIV(5): 1869-1874.

Nearing MA, Foster GR, Lane LJ, Finker SC. 1989. A process-based soil erosion model for USDA-Water Erosion Prediction Project technology. Transactions of 
the American Society of Agricultural Engineers, 32: 1587-93.

Rothacker L, Dosseto A, Francke A, Chivas A, Vigier N, Kotarba-Morley AM, Menozzi D. 2018. Impact of climate change and human activity on soil landscapes over the past 12,300 years. Scientific Reports, 8(1): 247.

Rumelhart D, Zipser D. 1985. Feature discovery by competitive learning. Cognitive Science, 9: 75-112.

Selby MJ. 1987. Rock slopes. In: Anderson MG, Richards KS. (eds.): Slope Stability. Wiley, Chichester, 475-504.

Sparks BW. 1965. Geomorphology. Longmans UK, 371 p.

Stocking MA, Elwell HA, 1973. Soil erosion hazard in Rhodesia. Rhodesian Agricultural Journal, 70: 93-101.

Thornes JB, Shao JX, Diaz E, Roldan A, McMahon M, Hawkes JC. 1996. Testing the MEDALUS hillslope model. Catena, 26(3-4): 137-160.
Underhill JR. 1989. Late Cenozoic deformation of the Hellenide foreland, Western Greece, Geological Society of America Bulletin, 101: 613-634.

Van der Knijff JM, Jones RJA, Montanarella L. 2000. Soil erosion risk assessment in Europe. European Soil Bureau, European Commission, 54p.

Verginis S. 1976. Monographie der insel Lefkon under Besonderer berucksichtigung der hydrologischen verhaltnisse. Wien, $190 \mathrm{p}$.

Wischmeier WH, Smith DD, 1978. Predicting rainfall erosion losses. USDA Agricultural Research Service Handbook, $537 \mathrm{p}$.

Zimmermann HJ. 1991. Fuzzy Set Theory and Its Application. 2nd edition, Kluwer Academic, MA. 